\title{
Design Fabrication and Testing of a Viscometer for Testing Viscosity of Liquids
}

\author{
Ekele Ogwu Augustine*, Ochei Emeka Stephen, Igbax Saanyol Ityokumbul \\ *1,2Engineering Materials Research Department, \\ Nigerian Building and Road Research Institute, Ogun State, Nigeria. \\ ${ }^{3}$ Tennessee Technological University, Cookeville, USA
}

\begin{abstract}
Viscosity plays an important role in sciences and engineering world. Knowledge of viscosity and flow parameters are essential in liquids for their production, quality control and development. The construction industry makes use of different liquids for different applications. Plasters, sealers bond breakers, liquid floor hardeners, coatings and more are liquids used in the construction industry. Conclusions about their processing characteristics, pumpability, sprayability shelf life, as well as flowability and application characteristics can be retrieved from successful measurements. It is therefore important that related measurements should be carried out with equipment that is accurate and less expensive. This paper presents the design, fabrication and testing of a viscometer that measures viscosity of fluids by virtue of its flow rate through a discharge orifice. The following considerations was used in designing the viscometer; corrosion resistance for selection of materials, ease of fabrication and usage. The fabricated viscometer was used to test kerosene, ethanol and plasma and yielded the following results; $\mathbf{0 . 0 0 1 3 4}$, 0.0011 and 0.0034 respectively. These values compare closely with different literatures and a significant average percentage error of $5.9 \%$. This proves that the viscometer produced is reliable and conforms to standards and can be used in laboratories, construction industries, food processing industries and for educational purposes.
\end{abstract}

Keywords-Corrosion resistance, pumpability, shelf life, sprayability, viscometer

\section{INTRODUCTION}

Not all liquids are the same; some a thin and flow fast while some are thick or gooey and flow slowly. The property that accounts for these differences in properties of flow is known as viscosity. [1] Defines viscosity as the measure of its resistance to deformation at a given rate which corresponds to the informal concept of thickness for liquids. The international systems of units (SI) measures the unit of viscosity in newton seconds per meter squared $\left(\mathrm{Ns} / \mathrm{m}^{2}\right)$ which is synonymous to a Pascal second (Pa s). The imperial units measures viscosity in pounds-force second per foot squared ibfs/ $\mathrm{ft}^{2}$ [2]. The study of this property of substances is known as rheology. This property is measured with a viscometer which provides data that are useful in quality control applications in the production of a wide variety of products including inks, paints, motor oils, food and cosmetic [3].

[4] Asserted that viscosity is a thermodynamic variable varying as a function of pressure and temperature. The viscosity of gases increases with increasing temperature due to increased interaction between gas molecules while in liquids the viscosity decreases with increasing temperature due to the increased spacing between molecules. Because of the numerous application of this effect of temperature change in viscosity, research works have given rise to empirical method of expressing the relationship between kinetic viscosity and temperature.

$$
\log _{10}(v+0.8)={ }_{n} \log _{10} T+C
$$

Viscosity measurement is very important in the world of science. Some of these areas where viscosity measurements are important are hydraulics, lubrication, construction, refrigeration and fabrication. In lubrication, lubricating oils are of different grades and these grades are determined greatly by their viscosity. Hence, according [5] viscosity is considered as a major property of lubricating oil. In the construction industry viscosity measurement is important in paint industries for quality control, production of adhesives and in concreting, viscosity determines self-leveling and pumping behavior of a mix. Viscometers are used to measure viscosity and there are of seven different classes. These are; capillary viscometers, orifice viscometers, high temperature high shear rate viscometers, rotational viscometers, falling ball viscometers, vibrational viscometers and ultrasonic viscometers. [6] Asserted that the commonly used viscometers are the capillary flow type, the orifice type and the rotational viscometers. Currently most commonly used viscosity measurements techniques require that the liquid comes in contact with a solid material. This method is in most cases impracticable for very thin liquids. The falling sphere viscometer is one of these commonly used techniques for measuring viscosity [7]. In this technique, a sphere of a known diameter is dropped in tube containing the liquid which viscosity is to be measured. If the density of the liquid is known, the viscosity can be determined from the terminal velocity of the sphere by using stokes law in equation 2

$$
6 \pi \mu U_{t} R+4 / 3 \pi R^{3} \rho g=4 / 3 \pi R^{3} \rho_{p} g
$$

Where $\rho$ is the density of the fluid

$$
\begin{aligned}
& \rho_{p} \text { is the density of the sphere } \\
& U_{t} \text { is the terminal velocity }
\end{aligned}
$$

The rotating viscometer is another method for viscosity determination. The rotating viscometer is a cylinder within another larger cylinder where the gap of the cylinders is filled with a liquid and one of the cylinders is rotated with a force [8]. Application of equations for coquette flow the viscosity can be determined by the velocity of the rotating cylinder.

Some of these viscometers make use of complex experimental methods for determining viscosity, also as a result of short 
dropping time as in the falling sphere viscometer, it is only recommended for fluids with viscosity equal to or greater than castor oil at room temperature. The commonly used viscometers are the orifice based viscometers [6]. These types of viscometers are used widely in paint and oil based industries. It consists of a reservoir, an orifice and a receiver. These viscometers measures viscosity in units of efflux time as the measurements consists of measuring the time it takes for a given fluid to travel from the orifice to the receiver. One major drawback of the instrument is that the set- up does not ensure that the pressure on the liquid remains constant and there is energy lost to friction at the orifice. Hence, this work is aimed at the development of an orifice apparatus that will ensure constant pressure during usage by incorporating a liquid feeder and an excess liquid drain pipe. This can be used an instrument for quality control in construction and other industries making use of liquids. This can also be used in laboratories to test viscosities of newly developed products in the industry.

\section{MATERIALS AND METHOD}

\section{A. Materials}

The apparatus consists of a cylindrical liquid container, a water bath, the liquid feeder, the rigid stand, beaker and stop watch. The material used for the fabrication and testing of the apparatus are:
i. mild steel angle iron
ii. Stainless steel hollow pipe
iii. Galvanised steel metal sheet
iv. Mild steel billet
v. Beaker
vi. Stop watch and test liquids

\section{B. Design and Material Selection for Components}

The various components were designed based on the following considerations.

i. Liquid container: The material used for the liquid bath should be corrosion resistant, good conductor of heat and should be easily available at a cheap cost. Stainless steel was found worthy and was used for the liquid bath.

ii. The dimension for the liquid bath was considered by getting a hollow cylinder of $5.0 \mathrm{~cm}$ internal diameter that can hold $500 \mathrm{ml}$ of liquid. The required length was calculated to be $25.4 \mathrm{~cm}$. $25.4 \mathrm{~cm}$ was cut from a stainless steel pipe of $5 \mathrm{~cm}$ internal diameter using a hack saw. Both ends of the pipe were ground for smoothness.

iii. The water bath: The material used for the water bath should be corrosion resistant, have good manufacturing properties, light weighted and should be readily available and cheap. Galvanized steel was chosen for the water bath. Considering the liquid container with two boiling rings on either side of the liquid container all in the water bath, the diameter was calculated to be $19.3 \mathrm{~cm}$. Considering clearance of $8 \mathrm{~cm}$ then the diameter of the water bath was taken to be $27.3 \mathrm{~cm}$. The length of the sheet used to obtain a cylinder of $27.3 \mathrm{~cm}$ diameter was computed using;
Length of the sheet =circumference of the cylinder $=\pi \mathrm{d}(3)$ " $\mathrm{d}$ " is the diameter of the cylinder and " $\pi$ " is 3.14 The dimension of the sheet used to make the water bath was marked out on a galvanized sheet of $1 \mathrm{~mm}$ thickness using a scriber. The marked out portion was cut out using a trimming machine. The galvanized sheet was rolled and the ends were joined into a cylinder by knitting manually. The base of the cylinder was marked and cut. A bore of $2.6 \mathrm{~cm}$ was made at the center of the base. This opening is the slot for the orifice billet. The base was put in its position.

iv. Rigid Stand: The material selected for the rigid stand was mild steel angle iron because of its rigidity. The dimension of the angle bar used was $5 \mathrm{~cm} * 5 \mathrm{~cm} * 0.01 \mathrm{~cm}$ thickness. $520 \mathrm{~cm}$ was cut from the original length of a mild steel angle bar. The $520 \mathrm{~cm}$ bar was cut into pieces to the required dimensions using a hack saw. The parts were welded together using electric arc welding machine

v. Orifice Billet: Mild steel was used for the billet for the orifice because of its good manufacturing properties. $2.3 \mathrm{~cm}$ was marked and cut from a mild steel billet of $2.6 \mathrm{~cm}$ diameter. A drilling machine with a drill bit of $2 \mathrm{~mm}$ diameter was used to drill through the billet at the center.

\section{EXPERIMENTAL PROCEDURE, RESULTS AND DISCUSSION}

\section{A. Experimental Procedure}

The materials used for the testing of the apparatus are; the test liquids (water, ethanol, kerosene and plasma), glass beaker and a stop watch. The apparatus was cleaned and set up as shown in appendix A. The orifice was closed and water was put into the liquid container. The feeder tap was also closed and filled with water. Both taps were open and water was collected from the liquid container in a glass beaker. The time taking to discharge $50 \mathrm{ml}, 75 \mathrm{ml}, 100 \mathrm{ml}, 125 \mathrm{ml}$ and $150 \mathrm{ml}$ of water was recorded. Each trial was carried out three times to avoid random error. These readings were recorded and the average time was also recorded. The same experiment was carried out with the test liquids in three trials and the average time readings were recorded as shown in table 3.2

\section{B. Theory}

Hagen poiseuille gives us a law relating viscosity of a fluid to the rate of flow as;

$$
\mu=\frac{P \pi r^{4}}{8 Q L}
$$

$$
\begin{aligned}
& \text { Where; } \mu=\text { viscosity } \\
& \mathrm{P}=\text { Pressure gradient } \\
& \mathrm{r}=\text { radius of pipe } \\
& Q=\text { flow rate } \\
& \mathrm{L}=\text { length of } \\
& \mathrm{P}, \mathrm{r}, \mathrm{L}
\end{aligned}
$$$$
\text { pipe }
$$ 
and $\pi$ are constants.

equation 3 becomes;

$$
\mu \alpha \mathrm{Q}
$$

Then for two dissimilar liquids then equation 4 can be rewritten as

$$
\frac{\mu_{1}}{\mu_{2}}=\frac{Q_{1}}{Q_{2}}
$$

And $\mathrm{Q}=$ volume of liquid discharged /time

It then follows that given two pairs of liquids of which the viscosity of one at room temperature is known (water for example) the ratio of their viscosities equals the slope of a graph volume discharged against time of discharge from the experiment conducted.

\section{Results and discusion of results}

Table 3.2: Experimental Results

\begin{tabular}{|l|l|l|l|l|}
\hline $\begin{array}{l}\text { Volume } \\
(\mathrm{ml})\end{array}$ & $\begin{array}{l}\text { Water } \\
\text { Time } \\
(\mathrm{sec})\end{array}$ & $\begin{array}{l}\text { Kerosene } \\
\text { Time } \\
(\mathrm{sec})\end{array}$ & $\begin{array}{l}\text { plasma } \\
\text { Time } \\
(\mathrm{sec})\end{array}$ & $\begin{array}{l}\text { Ethanol } \\
\text { Time } \\
(\mathrm{sec})\end{array}$ \\
\hline 50.00 & 9.5 & 6.25 & 63.75 & 2.36 \\
\hline 75.00 & 13.24 & 10.42 & 95.12 & 3.54 \\
\hline 100.00 & 18.56 & 13.06 & 126.00 & 4.71 \\
\hline 125.00 & 21.15 & 16.57 & 158.00 & 5,89 \\
\hline 150.00 & 27.58 & 21.08 & 188.00 & 7.10 \\
\hline
\end{tabular}

The results of the experiment conducted are presented in table 3.2. The graphical representation of the data are reflected in figures $1-4$

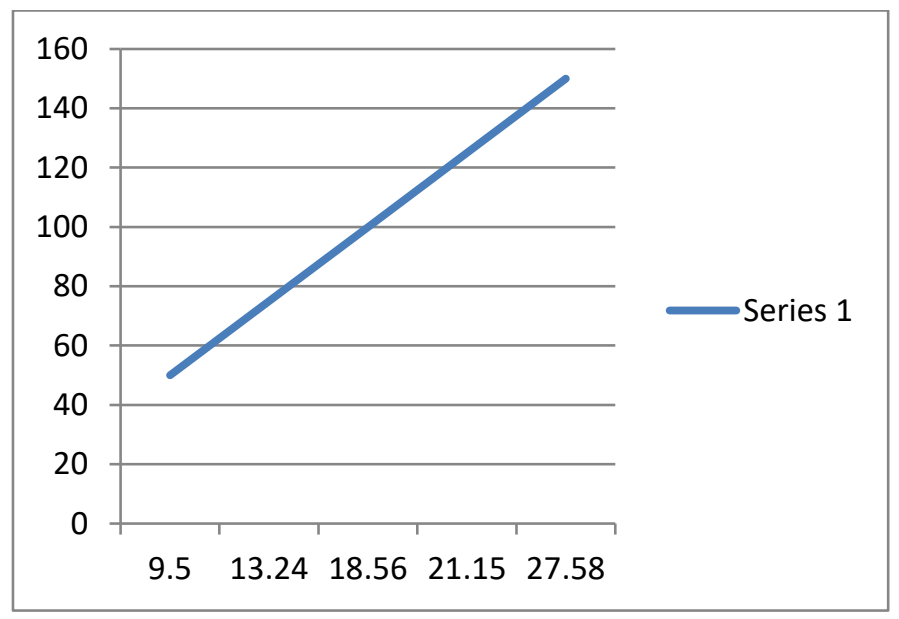

Figure 1: Graph of volume against time for water

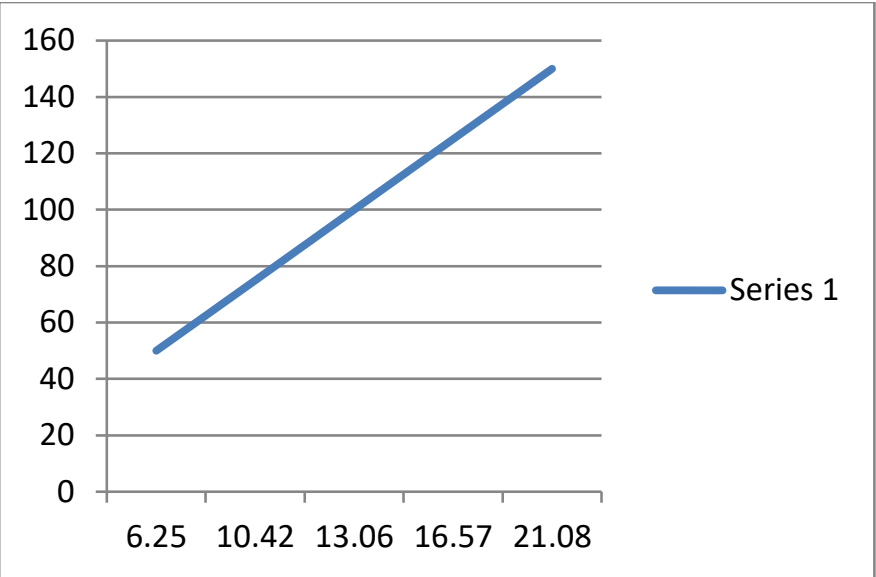

Figure 2: graph of volume against time for kerosene.

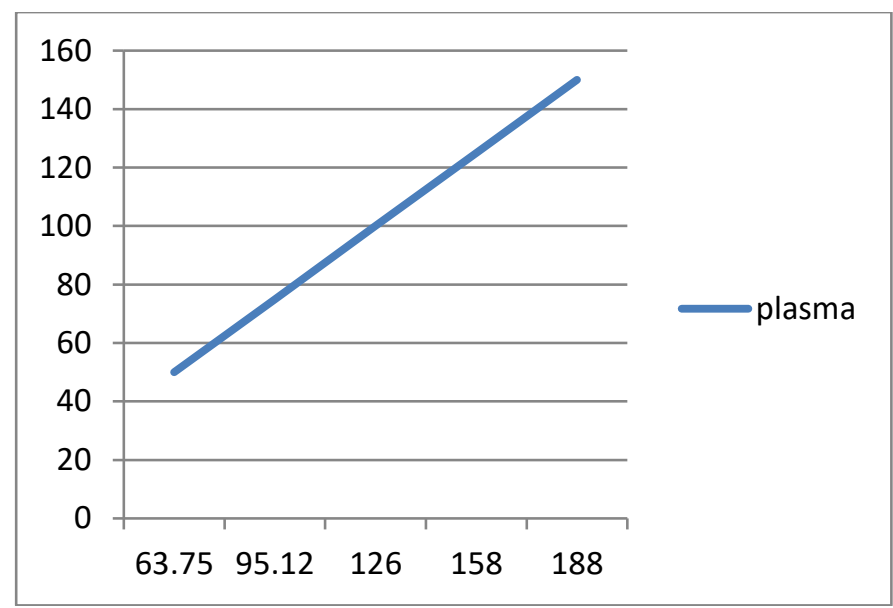

Figure 3: graph of volume against time of discharge for plasma

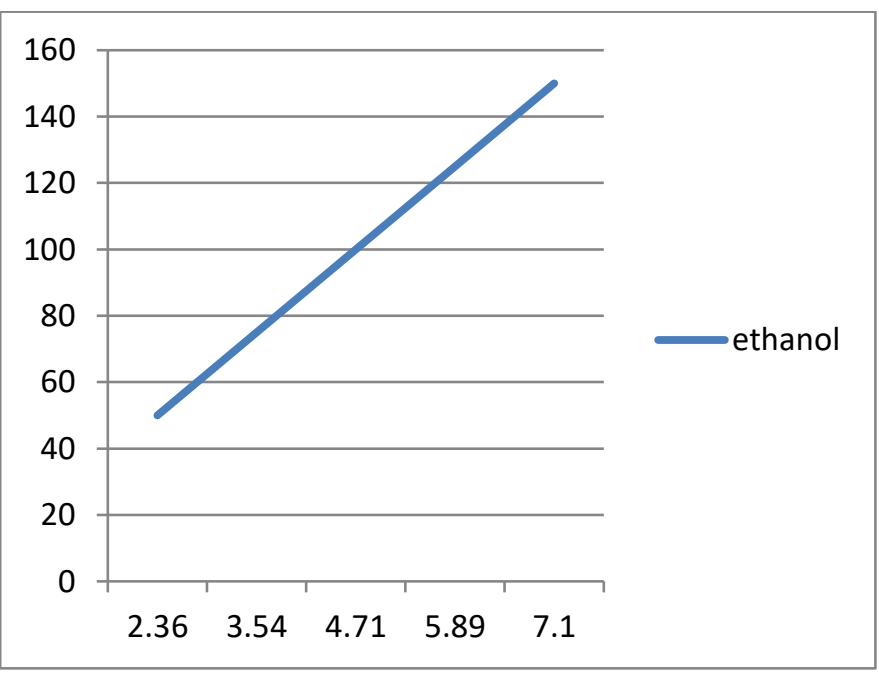

Figure 4: graph of volume against time for ethanol 
The graphs of volume discharge against time for different test liquids are shown in Figures 1- 4

From Figure.1, the slope which is Q for water was calculated to be $5.39 \mathrm{ml} / \mathrm{s}$

From Figure.2, the slope $\mathrm{Q}$ for kerosene was calculated to be $8.13 \mathrm{ml} / \mathrm{s}$.

From Figure.3, the sloe of the graph of plasma was calculated to be $0.806 \mathrm{ml} / \mathrm{s}$

From Figure 4, the slope of the graph for ethanol was calculated to be $21.1 \mathrm{ml} / \mathrm{s}$

From equation 5, using water of known viscosity of $0.00089 \mathrm{PaS}$, the viscosities for the various liquids were computed as reflected in table 3.3

Table 3.3: Experimental Values of Viscosity and Theoretical Values

\begin{tabular}{|l|l|l|}
\hline Tested liquid & $\begin{array}{l}\text { Experimental } \\
\text { viscosity Value } \\
(\mathrm{PaS})\end{array}$ & $\begin{array}{l}\text { Theoretical viscosity } \\
\text { value }(\mathrm{PaS})\end{array}$ \\
\hline Kerosene & 0.00134 & 0.00164 \\
\hline Ethanol & 0.0011 & 0.00109 \\
\hline plasma & 0.0034 & 0.00400 \\
\hline
\end{tabular}

The results shows a linear relationship between the volume of liquid discharged and time for the discharge as reflected in Figure1 to Figure 4. The test results shows that ethanol had the fastest rate of flow of through the orifice of $21.1 \mathrm{ml} / \mathrm{s}$ on the average. This is due to the low internal friction within the molecules of plasma compared to the other liquids while plasma had the slowest rate of flow of $0.806 \mathrm{ml} / \mathrm{s}$ on the average. This is due to the high internal friction existing within the molecules of the plasma. The average flow rates of kerosene and water were; $813 \mathrm{ml} / \mathrm{s}$ and $5.39 \mathrm{ml} / \mathrm{s}$ respectively.

From the slopes obtained, the viscosities of the test liquid were computed using equation 5 and are presented in table 3.3. And the percentage error of the viscometer fabricated was determined as

$$
\text { percentage error }=\frac{\text { actual value }- \text { expt value }}{\text { actual value }} \times 100
$$

This was calculated to be 1.8 percent, $0.9 \%$ and $15 \%$ for kerosene, ethanol and plasma respectively.

\section{Conclusion}

The viscometer which determines the viscosity of fluids by virtue of their rates of flow through a circular orifice was designed and fabricated. The viscometer was tested and was found to have an average percentage error of $5.9 \%$. This shows that the viscometer designed and fabricated is efficient and can be adopted for determining the viscosities of fluids.

\section{REFERENCES}

[1] Symon, K (1971). Mechanics (Third ed.). Addison- Wisley. ISBN 0201-07392-7.

[2] Godfrey, B.M. 2011. Experimental Results for Viscosity Measurement Performed on the International Space Station Using drop coalescence in Microgravity. Master's Thesis University of Tennessee, 2011. Retrieved from http://trace.tennessee .edu/uk_gradthes/972

[3] Building Construction Directory of Nigeria 2015

[4] White, F.M. (2003). Fluid Mechanics. New York, N.Y: McGraw Hill

[5] Fuller, D (1986). "Theory and Practical of Lubrication for Engineers" 2nd Edition Mc-Graw. Hill Book Company, New York, U.S.A R. Nicole, "Title of paper with only first word capitalized," J. Name Stand. Abbrev., in press.

[6] Abbas, K.A, Mohammed, A., Saleh, A.M. and Ebrahimian, M. (2010) "Suitability of Viscosity Measurement Methods for Liquid Food Variety and Applicability in Food Industry - A Review" Journal of Food Agriculture and Environment. Vol. 8 Pg 100-107.

[7] Sutterby, J. L. (1973). Falling Sphere Viscometer. Journal of Physics E: Scientific Instrument, 6 (10). .M. Young, The Technical Writer's Handbook. Mill Valley, CA: University Science, 1989.

[8] Dontula, P., Mascosko, C.W., and Scriven, L.E.,(2005). "Origin of Concentric Cylinders Viscometry” Journal of Rheology, 49 (4), 807.

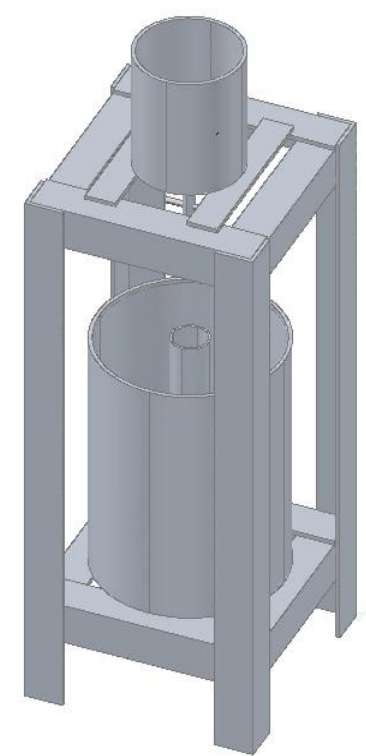

VISCOMETER 

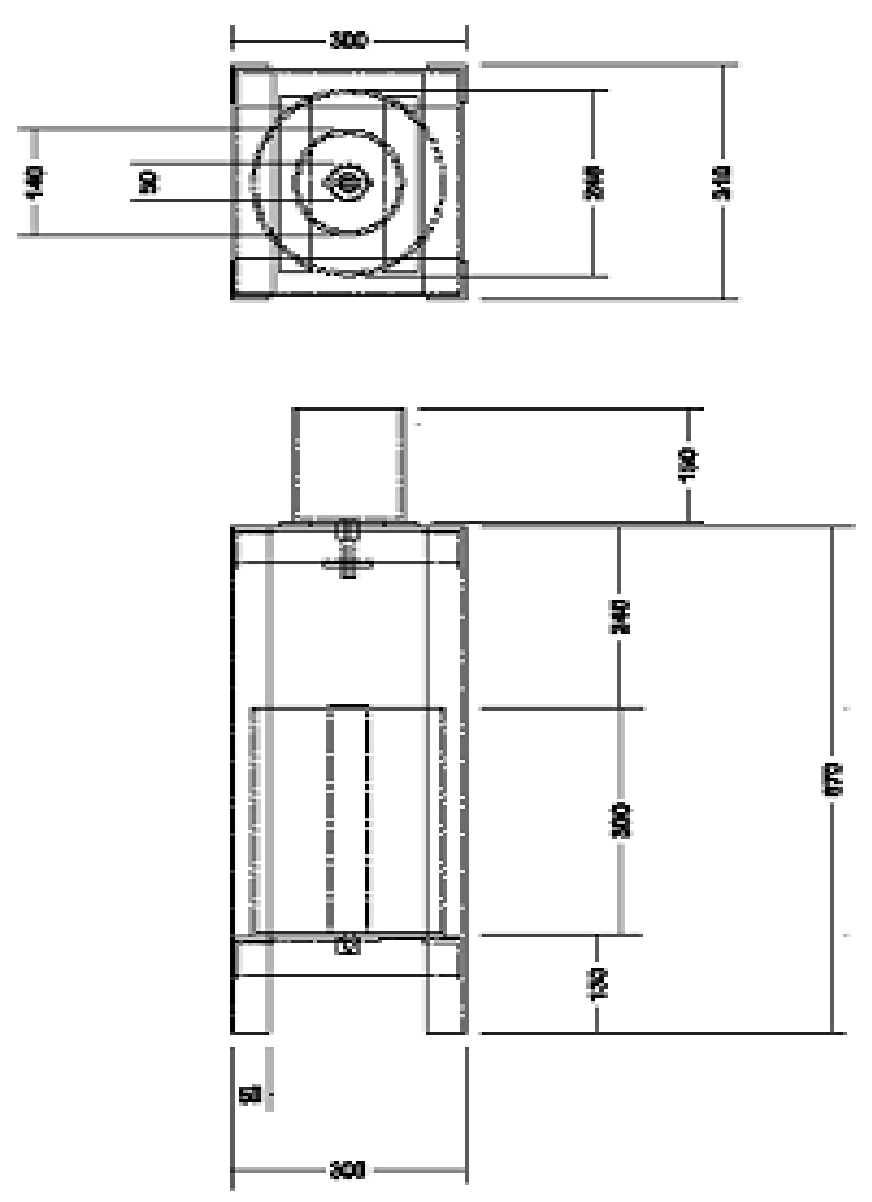

ORTHOGRAPHIC VIEWS OF THE VISCOMETER 